\title{
Episodic Hypoxia Promotes Defence Against Cellular Stress
}

\author{
Vicky Heßa Mumtaz Kasim ${ }^{a}$ Susanne Mathia ${ }^{a, b}$ Pontus B. Persson ${ }^{a}$ \\ Christian Rosenberger ${ }^{b} \quad$ Michael Fähling $^{a}$
}

aDepartment of Vegetative Physiology, Charité - Universitätsmedizin Berlin, Corporate Member of Freie Universität Berlin, Humboldt-Universität zu Berlin and Berlin Institute of Health, Berlin, bDepartment of Nephrology and Medical Intensive Care, Charité - Universitätsmedizin Berlin, Corporate Member of Freie Universität Berlin, Humboldt-Universität zu Berlin and Berlin Institute of Health, Berlin, Germany

\section{Key Words}

Episodic hypoxia $・$ Intermittent hypoxia - Cycling hypoxia $\cdot$ Hypoxia-inducible factor (HIF) • Cyclosporine $A \cdot$ Reactive oxygen species (ROS) $\bullet$ Apoptosis

\begin{abstract}
Background/Aims: Recently, we have demonstrated that episodic hypoxia occurs in kidneys of mice challenged repetitively with the immunosuppressant cyclosporine $\mathrm{A}(\mathrm{Cs} \mathrm{A})$, in analogy to humans on CsA treatment. However, the molecular consequences of episodic hypoxia remain poorly defined, as is its impact on cell survival. Here, we systematically study cell response to episodic, as compared to single course hypoxia. Methods: In vivo, kidneys of mice challenged daily with CsA for one week were analyzed by microarray analysis, gene ontology analysis, and qPCR. In vitro, renal cells were subjected to hypoxia $\left(1 \% \mathrm{O}_{2}\right)$ which was either episodic ( $4 \mathrm{~h}$ for 6 consecutive days), short-term (4 h), or sustained ( $24 \mathrm{~h}$ ). Western blot analysis quantified hypoxia-inducible factor-1 $\alpha$ (HIF-1 $\alpha$ ). 2', $7^{\prime}$-dichlorofluorescein diacetate detected intracellular ROS. After re-oxygenation, staurosporine served to induce apoptosis, quantified by active caspase-3. Results: In vivo, HIF target gene expression was suppressed by daily CsA treatment. Yet, we found up-regulation of genes involved in defence against cellular stress, notably against ROS. Renal cells in vitro behaved largely different under episodic and sustained hypoxia, while their response to short-term hypoxia oscillated between the previous two. Episodic hypoxia exhibited the highest total HIF-1 $\alpha$ protein level, lowest nucleus-tocytoplasm ratio, and lowest HIF target gene expression. When compared with normoxia, reoxygenation after sustained hypoxia increased ROS by $3.04 \pm 1.04$ fold $(p<0.001)$, and reoxygenation after episodic hypoxia by $1.26 \pm 0.16$ fold $(p<0.01)$. Staurosporine-induced active caspase- 3 was highest after sustained, and lowest after episodic hypoxia. Conclusion: In vitro episodic hypoxia mimics the largely HIF-independent transcriptome observed after repetitive CsA treatment in vivo. In vitro preconditioning with episodic hypoxia protects against stress-
\end{abstract}

V. Heß and M. Kasim contributed equally to this work. 
induced apoptosis. Despite of its long-term adverse effects, CsA derived episodic hypoxia induces a unique renal hypoxia response that provides adaptation to re-oxygenation mediated ROS damage.

(c) 2019 The Author(s). Published by Cell Physiol Biochem Press GmbH\&Co. KG

\section{Introduction}

Cellular injury caused by hypoxia-re-oxygenation $(H / R)$ is immanent in organ transplantation, and in various ischemic diseases. Cycles of H/R may occur chronically, as in obstructive sleep apnea, or in preterm infants with immature respiratory control [1-3]. Cellular H/R is also a key player in ischemia/reperfusion injury that leads to organ damage [4]. Key mediators of H/R injury are cellular hypoxia and the generation of reactive oxygen species (ROS). Hypoxia boosts hypoxia inducible factors (HIF), which elicit canonical transcriptional activation of survival genes promoting adaptation to decreased oxygen levels. HIF is a heterodimeric oxygen-sensing transcription factor consisting of a regulated alpha subunit (HIF- $\alpha$ ) and a constitutively expressed beta subunit (HIF- $\beta$ ). Under normoxic conditions, oxygen-dependent hydroxylation of HIF- $\alpha$ subunit by prolyl hydroxylase domain containing proteins (PHD) targets HIF- $\alpha$ for degradation by the proteasome [5]. While three different isoforms of HIF- $\alpha$ exist (HIF- $1 \alpha, 2 \alpha, 3 \alpha$ ), HIF- 1 and HIF-2 are primarily responsible for target gene activation in hypoxia [6, 7]. In general, HIF-1 is responsible for the initial response to hypoxia with HIF-2 coordinating the gene response under more prolonged hypoxic conditions in specific cell types $[8,9]$. Recently, we have shown that treatment with the immunosuppressant cyclosporine A (CsA), which is standard of care in organ transplantation [10], in mice leads to transient renal hypoxia, as revealed by pimonidazole adducts, deoxygenated hemoglobin content, and accumulation of HIF-1 $\alpha$ [11]. Since with repetitive CsA treatment the above mentioned hypoxia markers largely oscillated within $24 \mathrm{~h}$, we proposed the term "episodic hypoxia", in order to delimitate this from continuous hypoxia generally employed in experimental models. The reasons for CsA-induced organ hypoxia are incompletely understood, but most likely include vasoconstriction [12] and generation of reactive oxygen species (ROS) [13]. In both, humans and rodents, chronic CsA treatment eventually leads to renal toxicity with so-called striped tubular-interstitial fibrosis. This is highly suggestive of a hypoxic cause, given the poor physiological oxygen supply to medullary rays [14]. Nevertheless, the mechanisms leading to CsA-induced kidney fibrosis are still incompletely understood. It has been proposed that in hypoxic areas, such as medullary rays, HIF would promote fibrosis through pro-fibrotic target genes [15-17]. Interestingly, in some tumor cells it has been shown that CsA acts as a potent inhibitor of HIF$1 \alpha$ expression by accelerating the VHL-independent proteasomal degradation of the protein [18]. Moreover, in C6 glioma cells, CsA prevented HIF-1 $\alpha$ stabilization during hypoxia and, thus, inhibited HRE (hypoxia response element)-mediated hypoxic adaptation [19]. In line with a limited renal HIF response in CsA mediated episodic hypoxia in vivo, we found low HIF target gene levels, however, despite of a marked up-regulation of HIF- $1 \alpha$ protein [11]. It is unclear whether such disparity is specific for CsA treatment or a general phenomenon in episodic hypoxia, as are potential cell protective responses. In this study, we replicate episodic hypoxia in vitro, and systematically assess its consequences. We find that episodic hypoxia generates a specific, HIF-independent transcriptome, which confers resistance against cellular stress, and protects against apoptosis. 


\section{Materials and Methods}

\section{Animal Studies}

Animal experiments were carried out according to the guidelines of the American Physiological Society. Pax8-erTA/LC1/VHL ${ }^{\text {flox }+/+}$ mice were used throughout, and experimental protocols for mice were as previously described [20,21]. In order to obtain robust and sustained HIF up-regulation, VHL-KO was induced by a single SC injection of doxycycline, and kidneys were harvested $4 \mathrm{~d}$ later. This time lag was necessary to allow full establishment of the knock-out. Kidneys from untreated animals served as controls. In order to induce in vivo episodic hypoxia, seven daily SC injections of CsA (60 mg/kg) were delivered, and kidneys harvested $2 \mathrm{~h}$ after the last injection. Control animals received the CsA solvent cremophore [11]. Animal experiments with CsA were conducted without doxycycline induction.

\section{Cell culture and in vitro hypoxia protocols}

Mouse distal convoluted tubule (DCT) cells (gift from Dr. Peter A. Friedman) were cultured in RPMI medium supplemented with $10 \%$ heat-inactivated fetal bovine serum (FBS). Human fibrosarcoma (HT1080) cells (DSMZ, Germany; ACC 315) were grown in Dulbecco's modified Eagle's medium, supplemented with $10 \mathrm{mM}$ Hepes and $10 \%$ FBS. Cells were cultured under normoxia $\left(21 \% \mathrm{O}_{2}, 5 \% \mathrm{CO}_{2}, 37^{\circ} \mathrm{C}\right)$ or placed in a hypoxia incubator $\left(1 \% \mathrm{O}_{2}, 5 \% \mathrm{CO}_{2}, 37^{\circ} \mathrm{C}\right)$. Three in vitro hypoxia protocols were used (Fig. 1): Short-term hypoxia was chosen to replicate a single injection of CsA in mice, which led to a marked accumulation of hypoxia markers by $2 \mathrm{~h}$ [11]. Incubation time in vitro was set at $4 \mathrm{~h}$, appreciating that some additional time would be needed for ambient oxygenation to reach its designated level. In mice, episodic hypoxia had consisted of 7 daily doses of CsA, with kidneys harvested $2 \mathrm{~h}$ after the last dose [11]. In vitro, we opted for 6 daily courses of short-term hypoxia ( $4 \mathrm{~h}$, see above), with cell harvesting immediately after the last course. Although this was one day short of the corresponding in vivo experiment, we felt it was appropriate, since combined hypoxia time thus matched the $24 \mathrm{~h}$ of sustained hypoxia, the third protocol employed. The latter was chosen as the benchmark of hypoxia research.

\section{Microarrays/gene ontology (GO)-Analysis}

Total RNA was extracted using RNA Bee (Biozol Diagnostica Vertrieb GmbH) from halved kidneys harvested from control $(n=5)$ and CsA treated $(n=5)$ mice. The integrity of the prepared RNA was checked on a 2100 Bioanalyzer (Agilent Technologies) prior to submission to the Charité Genome Analysis Facility for global gene expression analysis using the Affymetrix Mouse Gene ST 2.0 (Affymetrix Inc.). Microarray data were submitted to the Gene Expression Omnibus [GSE111516].

Microarray data served for functional enrichment analysis using the Web-based Gene Set Analysis Toolkit (WebGestalt) [22]. Enrichment analysis of gene sets that were significantly either upregulated or downregulated in control animals or mice following one week of daily CsA treatment was performed based on the Gene Ontology, KEGG Pathway, and WikiPathways databases. To ensure high stringency, we selected groups of regulated genes according to a p-value $<0.01$.

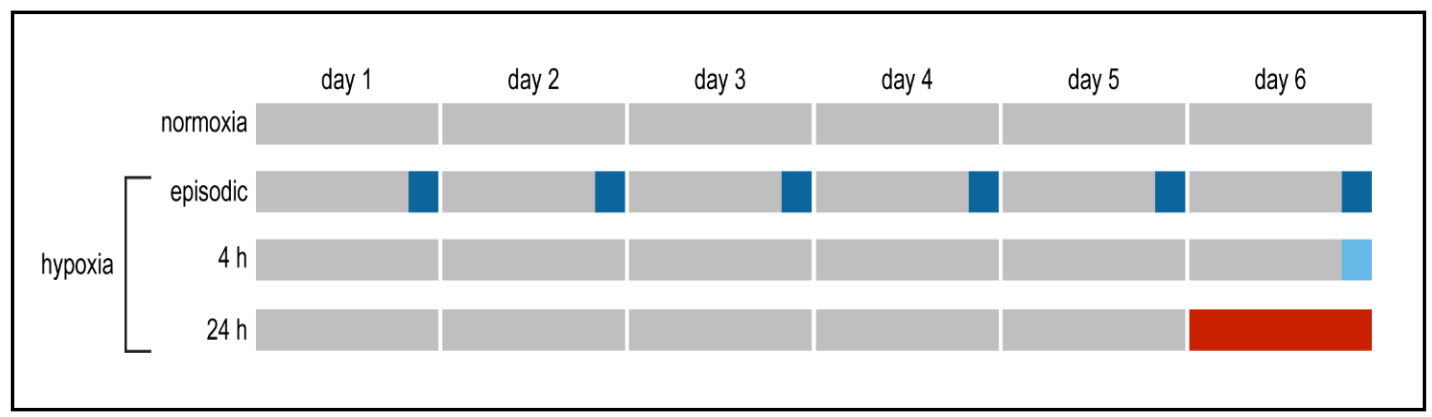

Fig. 1. Schematic of the experimental in vitro design used to create the different models of hypoxia. Renal (DCT) cells exposed to periods of normoxia are shown as grey boxes, short periods of 4 h hypoxia as short blue boxes, and sustained $24 \mathrm{~h}$ hypoxia as a longer red box. Note that episodic hypoxia, which consists of 6 daily doses of $4 \mathrm{~h}$ hypoxia each, is shown in a darker shade of blue. 


\section{RNA extraction and $q P C R$}

Total RNA was extracted using RNA-Bee (Biozol Diagnostica Vertrieb GmbH). mRNA levels were quantified by real time PCR measurements and performed in triplicates (StepOnePlus, Applied Biosystems). PCR steps were defined as follows: $10 \mathrm{~min}$ at $95^{\circ} \mathrm{C}$ and 40 cycles composed of $15 \mathrm{~s}$ at $95^{\circ} \mathrm{C}$, $1 \mathrm{~min}$ annealing at $62^{\circ} \mathrm{C}$, and $30 \mathrm{~s}$ elongation at $77^{\circ} \mathrm{C}$. When possible, primers were designed to span an exon junction. The primer sequences used are as following: 18S_rRNA_Fw: 5'-GATCAAAACCAACCCGGTCA; 18S_rRNA_Re: 5'-CCGTTTCTCAGGCTCCCTCT; AldoC_Fw: 5'-GCTGAGCCAAATTGGGGTGG; AldoC_Re: 5'-CCATCCAGCCCTTGAGTGGT; Hk2_Fw: 5'-GTGCATCGCGGACTTCCTTG; Hk2_ Re: 5'-GGCGAATGGCTTCCTTCAGC; Slc2a1_Fw: 5'-TCTTAAGTGCGTCAGGGCGT; Slc2a1_ Re: 5'-CTCCGTAGCGGTGGTTCCAT; Adm_Fw: 5'-CAGCAGCTACCCTACGGGAC; Adm_Re: 5'-CATCCATTGCTGCGGGAACC. mRNA expression levels were normalized to $18 \mathrm{~S}$ rRNA using the $\Delta \mathrm{C}_{\mathrm{t}}$ method. Results are shown as arithmetic means of at least three independent biological replicates.

\section{Protein Isolation and Western blot analysis}

Total protein extracts were isolated using a lysis buffer containing $50 \mathrm{mM}$ Tris (pH 6, 8), $4 \mathrm{M}$ urea, 1 $\%$ SDS, and $12.5 \mathrm{mM}$ DTT. For investigation of protein translocation to the nucleus, cytosolic and nuclear extracts were prepared by differential centrifugation at $10,000 \mathrm{x}$ g for $10 \mathrm{~min}$ in lysis buffer containing 20 mM Tris, $140 \mathrm{mM} \mathrm{NaCl}, 25 \%$ glucose, $0.1 \%$ SDS, $0.5 \%$ Nonidet $\mathrm{P} 40,1 \mathrm{x}$ complete protease inhibitor cocktail (Roche) and $1 \mathrm{mM}$ DTT. The S10 supernatant represented the cytoplasmic fraction. The resultant pellet (nuclear fraction) was washed in PBS, re-suspended in lysis buffer and boiled under shaking for 5 min at $95^{\circ} \mathrm{C}$. Western blotting was performed as previously described [23]. The following primary antibodies were used: anti-HIF-1 $\alpha$ (10006421, Cayman Chemical), anti-acetyl-Histone H3 (06599, Biomol), anti-Tubb2B (TA 337744, Origene), anti-caspase 3 (AM08377PU-N, Acris), and anti-active caspase 3 (3015-100, Biovision). Secondary antibodies used were donkey anti-rabbit and goat anti-mouse IgG-HRP (sc-2317 and sc-2031, Santa Cruz Biotechnology).

\section{Cell Transfection and Reporter Gene Assays}

Cells were grown in 96-well plates and transfected with the firefly luciferase pGL3-promoter vector (Promega) as a control or its modified variant containing 6 hypoxia responsive elements (6 x HRE) (5' RCGTG) for quantification of the transcriptional activity of HIF-1. Co-transfection of a renilla luciferase vector served as a control for transfection efficiency. Transfections were performed $12 \mathrm{~h}$ prior to the final hypoxia cycle (for in vitro hypoxia protocols see Fig. 1) using the PolyMag transfection reagent (Oz Biosciences) according to the manufacturer's instructions. Luciferase activity was detected using the Dual-Glo ${ }^{\circledR}$ assay system (Promega) and measured using the Synergy HTX multi-mode reader (BioTek Instruments GmbH).

\section{ROS assay in vitro}

Following either normoxia, $4 \mathrm{~h}$ of hypoxia, $24 \mathrm{~h}$ of hypoxia, or the last of 6 daily courses of 4 h hypoxia (episodic hypoxia), cells were treated under normoxic conditions with $10 \mu \mathrm{M}$ 2',7'-dichlorofluorescein diacetate (DCFDA, from Sigma) in serum-free media for $30 \mathrm{~min}$ in the dark, washed with PBS and allowed to recover in the presence of $0.03 \% \mathrm{H}_{2} \mathrm{O}_{2}$ for $30 \mathrm{~min}$. Fluorescence intensity was read on a Synergy HTX multimode plate reader (BioTek Instruments $\mathrm{GmbH}$ ). For each condition, 4 separate samples were used for cell counting. Fluorescence reads were normalized to cell number.

\section{Induction of apoptosis in vitro}

Following the above-described protocols, cells were treated with $1 \mu \mathrm{M}$ staurosporine (Sigma) for $3 \mathrm{~h}$ under normoxic conditions, followed by protein extraction and Western blot to detect apoptosis marker active caspase-3.

\section{Statistics}

All values are presented as mean \pm SD. Data were analysed by the unpaired t test or the ANOVA with post hoc Tukey test, as appropriate. $\mathrm{p}<0.05$ was considered significant. 


\section{Results}

\section{Episodic hypoxia creates a specific transcriptome in vivo}

Recently, we have shown in mice that repetitive CsA treatment provoked episodic hypoxia and up-regulation of the regulatory $\alpha$-subunit of the transcription factor HIF-1 [11]. However, marked up-regulation of HIF- $1 \alpha$ following CsA treatment, does not correlate with an elevated HIF response by detection of classical HIF-1 target genes. When comparing mRNA expression levels of HIF target genes in kidneys of mice following CsA treatment [11] with models of i) renal hypoxia (rhabdomyolysis induced acute kidney injury) [21] or ii) renal tubular HIF activation by VHL-KO [21], it can be demonstrated that the HIF response is absent in CsA mediated episodic hypoxia (Fig. 2).

Therefore, we here moved on to systematically analyze the transcriptome in CsA treated mice. By microarray analysis, we found 3,282 genes changed with a p-value of $\leq 0.01$ in kidneys of mice daily treated with CsA for one week. Of these, 1,471 genes were up-regulated

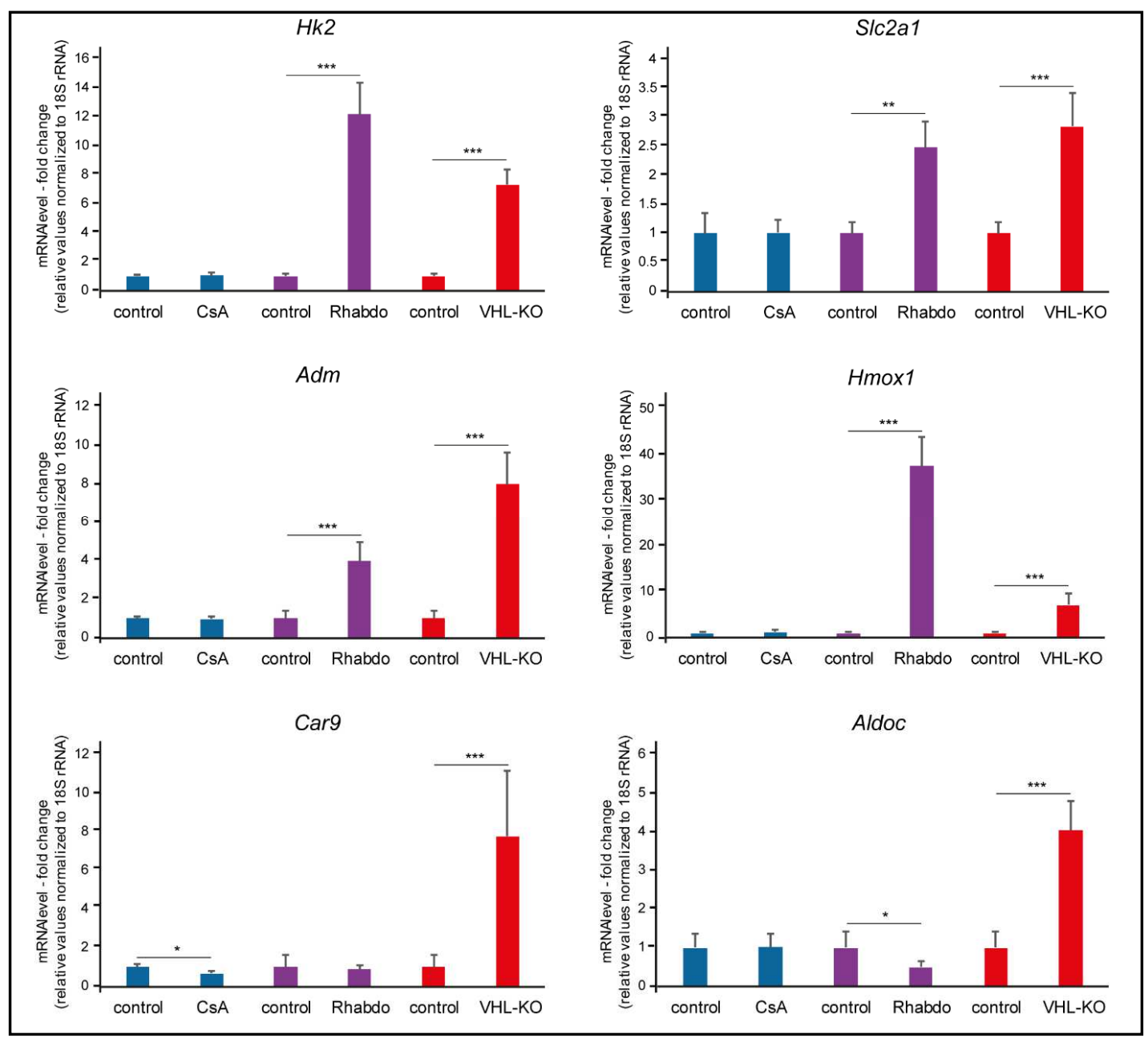

Fig. 2. HIF target genes elevated during renal hypoxia (Rhabdo) or renal HIF activation (VHL-KO) are not changed following CsA treatment. Quantification (qPCR) of renal expression of selected HIF target genes: hexokinase-2 (Hk2), Glucose-1 transporter (Slc2a1 alias Glut1), adrenomedullin (Adm), heme oxygenase-1 (Hmox1), carbonic anhydrase-9 (Car9) and aldolase C (Aldoc) in different in vivo settings. CsA: daily CsA treatment of mice (60 mg/kg BW) for one week as described and shown in [11]. Rhabdo: Rhabdomyolysis induced AKI in mice as a model of renal hypoxia as described and shown in [21]. VHL-KO: transgenic mice with inducible, tubulus specific VHL-knock out served as model of renal HIF activation as described and shown in [21]. *: p<0.05, **: $\mathrm{p}<0.01,{ }^{* * *}: \mathrm{p}<0.001$. 


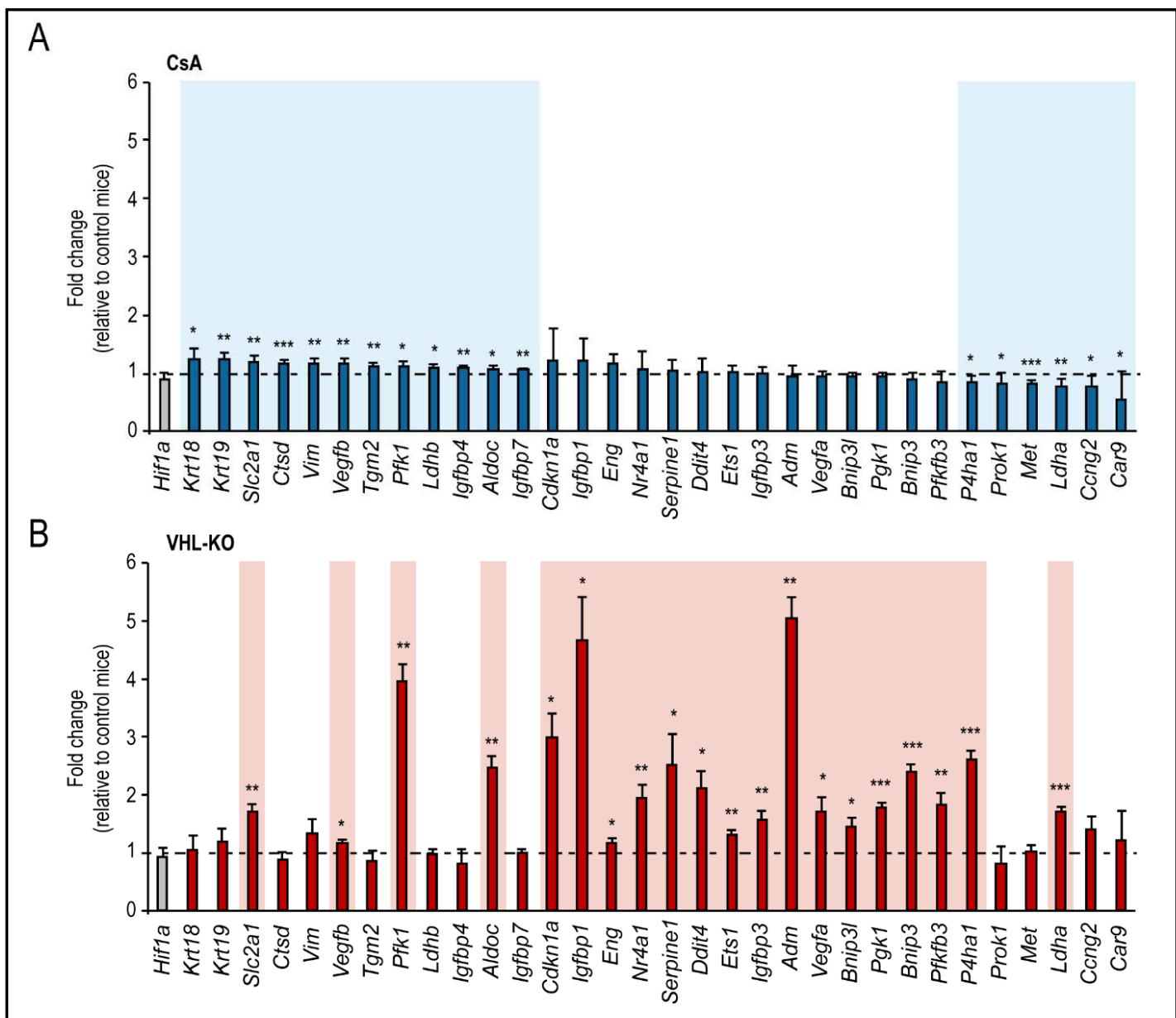

Fig. 3. CsA treatment in vivo leads to only modest activation of HIF-1 signaling. Yet, cellular defense against stress is promoted. (A) Fold changes and associated p-values for known HIF-1 target genes as determined from the microarray analysis are shown for CsA treated mice. (B) For comparison, a typical pattern of these HIF target genes is shown in mice expressing tubular VHL-KO, as a model of renal HIF response (data taken from GSE44925) [21]. *: p<0.05, **: $\mathrm{p}<0.01,{ }^{* * *}: \mathrm{p}<0.001$.

and 1,811 genes were down-regulated. In order to characterize the HIF transcriptional response at a more global level, 32 acknowledged HIF target genes with robust renal expression were selected. Fig. 3A depicts the modest activation of HIF target genes in CsAinduced episodic hypoxia. For comparison, and to demonstrate a typical renal HIF response, Fig. 3B shows the alteration of these HIF target genes in kidneys of inducible, tubular specific VHL-KO mice, a transgenic model that elicits prominent renal up-regulation of HIF target genes (see Fig. 2), [21]. In CsA-induced episodic hypoxia, up-regulation of HIF target genes was less frequent, far less prominent, and rarely matching the pattern seen by VHL-KO. Indeed, when performing gene ontology analysis we observed no significant association with the terms "HIF transcriptional response" or "response to hypoxia", indicating a lack of HIF response in CsA-induced episodic hypoxia. Instead, according to gene ontology analysis, up-regulated genes were significantly linked with the terms "Cytoplasmic Ribosomal Proteins" and "Translation Factors" (Table 1), indicating compensation of mRNA translation that normally is inhibited in hypoxia [24]. Furthermore, we found increased mRNA levels of factors involved in "Electron Transport Chain" and "Oxidative Phosphorylation", while downregulation of factors belonging to "TCA Cycle". 
Table 1. Pathways regulated in kidneys of mice following CsA treatment for one week (daily $60 \mathrm{mg} / \mathrm{kg} \mathrm{BW}$ ). Candidate genes that were either up- or down-regulated were selected from microarray data by significant regulation ( $\mathrm{p}<0.01)$. Enriched pathways (up-regulated: left side; down-regulated: right side) were obtained based on the Gene Ontology, KEGG Pathway, and WikiPathways databases at Web-based Gene Set Analysis Toolkit (WebGestalt). C: the number of reference genes in the category, $\mathrm{O}$ : the number of genes in the gene set and also in the category, E: the expected number in the category, R: ratio of enrichment, rawP: p-value from hypergeometric test, adjP: p-value adjusted by the multiple test adjustment

\begin{tabular}{|c|c|c|c|}
\hline \multicolumn{2}{|c|}{ CsA: $p<0.01$ UP } & \multicolumn{2}{|c|}{ CsA: $\mathrm{p}<0.01$ DOWN } \\
\hline PathwayName & $\begin{array}{l}\text { Statistics } \\
\end{array}$ & PathwayName & Statistics \\
\hline $\begin{array}{l}\text { Cytoplasmic Ribosomal } \\
\text { Proteins }\end{array}$ & $\begin{array}{c}\mathrm{C}=77 ; \mathrm{O}=48 ; \mathrm{E}=3.66 ; \\
\mathrm{R}=13.13 ; \operatorname{raw} \mathrm{P}=4.10 \mathrm{e}-44 ; \\
\operatorname{adj} \mathrm{P}=4.51 \mathrm{e}-42\end{array}$ & TCA Cycle & $\begin{array}{l}\mathrm{C}=32 ; \mathrm{O}=17 ; \mathrm{E}=2.09 ; \mathrm{R}=8.12 ; \\
\text { rawP=1.51e-12; adjP=1.75e-10 }\end{array}$ \\
\hline $\begin{array}{l}\text { Electron Transport } \\
\text { Chain }\end{array}$ & $\begin{array}{c}\mathrm{C}=99 ; \mathrm{O}=19 ; \mathrm{E}=4.70 \\
\mathrm{R}=4.04 ; \mathrm{rawP}=1.78 \mathrm{e}-07 \\
\text { adj } \mathrm{P}=9.79 \mathrm{e}-06\end{array}$ & mRNA Processing & $\begin{array}{c}\mathrm{C}=455 ; \mathrm{O}=57 ; \mathrm{E}=29.78 ; \mathrm{R}=1.91 ; \\
\text { rawP=1.93e-06; adj } \mathrm{P}=0.0001\end{array}$ \\
\hline Translation Factors & $\begin{array}{c}\mathrm{C}=49 ; \mathrm{O}=10 ; \mathrm{E}=2.33 \\
\mathrm{R}=4.30 ; \mathrm{rawP}=8.48 \mathrm{e}-05 \\
\text { adj } \mathrm{P}=0.0014\end{array}$ & $\begin{array}{l}\text { Diurnally regulated } \\
\text { genes with circadian } \\
\text { orthologs }\end{array}$ & $\begin{array}{c}\mathrm{C}=48 ; \mathrm{O}=13 ; \mathrm{E}=3.14 ; \\
\mathrm{R}=4.14 ; \mathrm{raw} \mathrm{P}=8.56 \mathrm{e}-06 \\
\text { adj } \mathrm{P}=0.0002\end{array}$ \\
\hline $\begin{array}{l}\text { Oxidative } \\
\text { Phosphorylation }\end{array}$ & $\begin{array}{c}\mathrm{C}=58 ; \mathrm{O}=11 ; \mathrm{E}=2.75 \\
\mathrm{R}=3.99 ; \mathrm{raw} \mathrm{P}=7.70 \mathrm{e}-05 \\
\text { adj } \mathrm{P}=0.0014\end{array}$ & Amino Acid Metabolism & $\begin{array}{l}\mathrm{C}=112 ; \mathrm{O}=21 ; \mathrm{E}=7.33 ; \mathrm{R}=2.86 \\
\operatorname{rawP}=1.08 \mathrm{e}-05 ; \operatorname{adj} \mathrm{P}=0.0002\end{array}$ \\
\hline Macrophage Markers & $\begin{array}{c}\mathrm{C}=10 ; \mathrm{O}=5 ; \mathrm{E}=0.47 \\
\mathrm{R}=10.53 ; \operatorname{rawP}=4.94 \mathrm{e}-05 ; \\
\text { adj } \mathrm{P}=0.0014\end{array}$ & Glycogen Metabolism & $\begin{array}{l}\mathrm{C}=35 ; \mathrm{O}=11 ; \mathrm{E}=2.29 ; \mathrm{R}=4.80 \\
\text { rawP=8.80e-06; adjP=0.0002 }\end{array}$ \\
\hline Focal Adhesion & $\begin{array}{c}\mathrm{C}=186 ; \mathrm{O}=22 ; \mathrm{E}=8.83 \\
\mathrm{R}=2.49 ; \mathrm{raw}=7.73 \mathrm{e}-05 \\
\text { adj } \mathrm{P}=0.0014\end{array}$ & Circadian Exercise & $\begin{array}{l}\mathrm{C}=49 ; \mathrm{O}=13 ; \mathrm{E}=3.21 ; \mathrm{R}=4.05 \\
\text { rawP=1.10e-05; adjP=0.0002 }\end{array}$ \\
\hline $\begin{array}{l}\text { Complement Activation, } \\
\text { Classical Pathway }\end{array}$ & $\begin{array}{c}\mathrm{C}=17 ; \mathrm{O}=6 ; \mathrm{E}=0.81 ; \mathrm{R}=7.43 \\
\operatorname{raw} \mathrm{P}=8.91 \mathrm{e}-05 \\
\operatorname{adj} \mathrm{P}=0.0014\end{array}$ & Insulin Signaling & $\begin{array}{c}\mathrm{C}=158 ; \mathrm{O}=24 ; \mathrm{E}=10.34 ; \mathrm{R}=2.32 ; \\
\text { rawP=9.79e-05; adj } \mathrm{P}=0.0016\end{array}$ \\
\hline Oxidative Stress & $\begin{array}{l}\mathrm{C}=28 ; \mathrm{O}=7 ; \mathrm{E}=1.33 ; \mathrm{R}=5.26 \\
\operatorname{rawP}=0.0003 ; \operatorname{adj} \mathrm{P}=0.0037\end{array}$ & Proteasome Degradation & $\begin{array}{c}\mathrm{C}=59 ; \mathrm{O}=12 ; \mathrm{E}=3.86 ; \mathrm{R}=3.11 \\
\text { raw } \mathrm{P}=0.0004 ; \operatorname{adj} \mathrm{P}=0.0058\end{array}$ \\
\hline Glutathione Metabolism & $\begin{array}{c}\mathrm{C}=54 ; \mathrm{O}=10 ; \mathrm{E}=2.56 \\
\mathrm{R}=3.90 ; \operatorname{raw} \mathrm{P}=0.0002 \\
\text { adjP=0.0031 }\end{array}$ & MAPK Signaling Pathway & $\begin{array}{l}\mathrm{C}=165 ; \mathrm{O}=22 ; \mathrm{E}=10.80 ; \mathrm{R}=2.04 ; \\
\quad \operatorname{rawP}=0.0012 ; \operatorname{adj} \mathrm{P}=0.0155\end{array}$ \\
\hline
\end{tabular}

"Focal Adhesion", “Macrophage Marker" and "Complement Activation, Classical Pathway" support the view of activation of the innate immune system under conditions of CsA, which blocks the adaptive immunity. Finally, "Oxidative Stress" and "Glutathione Metabolism” nicely fit into the picture of episodic hypoxia being a condition of hypoxia/ re-oxygenation that causes elevated ROS levels. Analysis of the down-regulated genes by CsA-induced episodic hypoxia yielded e.g. genes that are involved in circadian rhythms.

Taken together, in vivo CsA mediated episodic hypoxia creates a specific transcriptome, clearly distinct from that obtained by HIF activation and/ or sustained hypoxia.

\section{HIF-1 $\alpha$ accumulation and impaired transcriptional activity in episodic hypoxia in vitro}

Given the disparity between the abundance of HIF-1 $\alpha$ protein and the lack of HIF target gene expression in CsA-induced episodic hypoxia [11], we attempted to replicate this pattern in vitro using renal distal convoluted tubule (DCT) cells. To this end, cells were exposed to 1 $\% \mathrm{O}_{2}$ for $4 \mathrm{~h}$ per day on 6 consecutive days (episodic hypoxia). The results were compared with a single $4 \mathrm{~h}$ course of (short-term) hypoxia, as well as with $24 \mathrm{~h}$ of (sustained) hypoxia (see Fig. 1). The latter is the benchmark protocol for activation of HIF and HIF target genes.

We observed highest levels of HIF- $1 \alpha$ in mouse renal DCT cells following episodic hypoxia (Fig. 4A); a finding that was also observed in human HT1080 fibrosarcoma cells subjected to similar cycles of episodic hypoxia (Fig. 4B). No significant difference, however, was observed when comparing episodic hypoxia to cells exposed to a single $4 \mathrm{~h}$ cycle of hypoxia.

Using a HIF dependent luciferase reporter construct where the luciferase gene was cloned downstream of a promoter containing six hypoxia-response elements ( $6 \mathrm{x} \mathrm{HRE}$ ) (Fig. 5, left panel), we found that long-term hypoxia induced a $13.2(+3.8)-$ and $22.0(+$ 4.9)-fold increase in transcriptional activity at $24 \mathrm{~h}$ of hypoxia in DCT and HT1080 cells, 


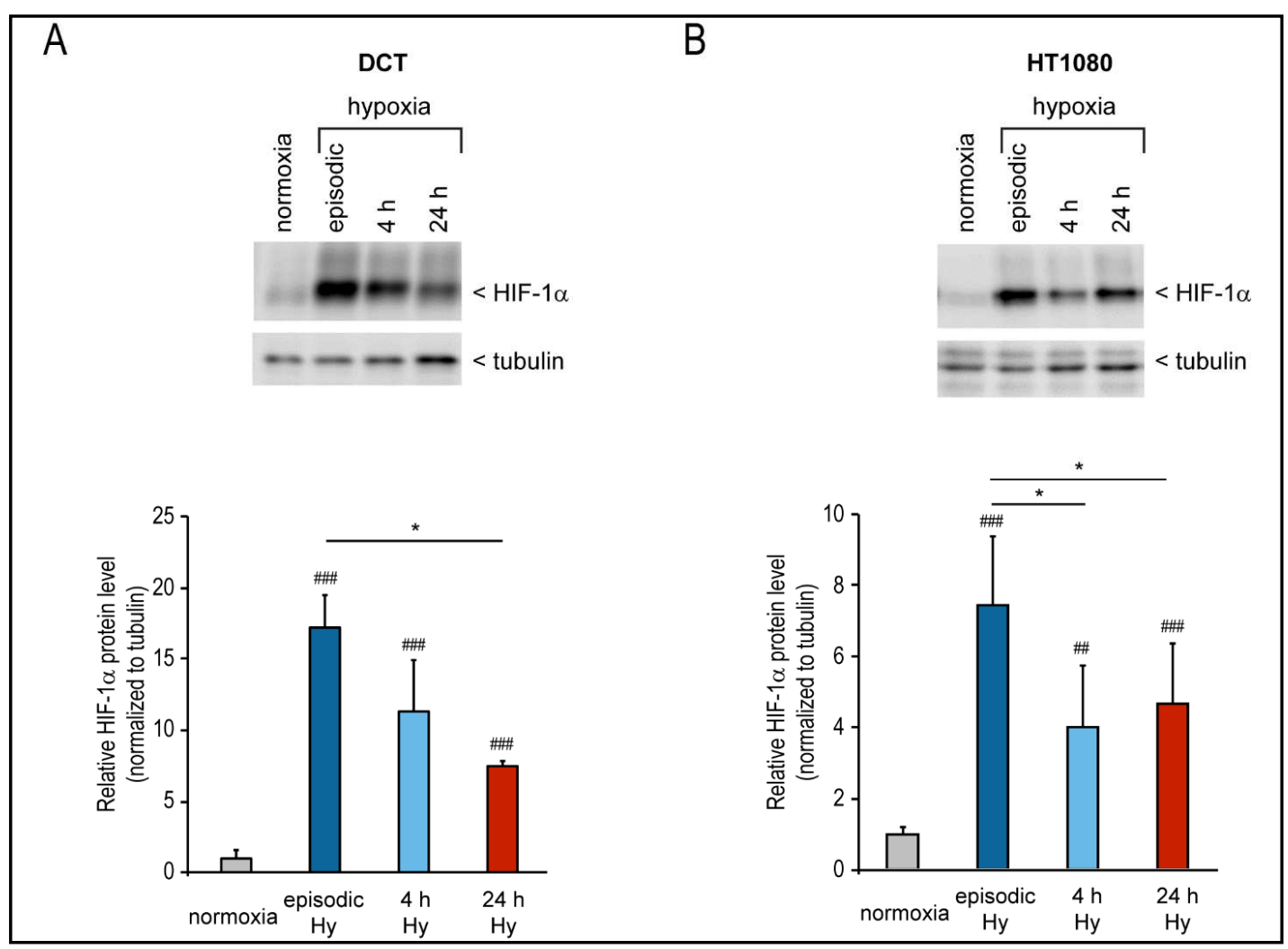

Fig. 4. Episodic hypoxia increases HIF-1 $\alpha$ protein levels. Western blot analysis of HIF-1 $\alpha$ protein levels (top panel) in (A) mouse renal cells (DCT) and (B) human fibrosarcoma cells (HT1080). Quantitation of the data is shown in the bottom panel. Detection of tubulin served as a loading control. Error bars indicate standard deviation $(n=3)$. Significance to normoxia \#\#: $p<0.01$, \#\#\#: $p<0.001$. Asterisks denote significance between hypoxic groups. *: p<0.05.

respectively. In comparison, episodic hypoxia induced only a $2.7(+1.0)-$ and $1.6(+0.5)$-fold increase in activity in DCT and HT1080, respectively. Values following episodic hypoxia were significantly $(\mathrm{p}<0.001)$ lower than those at $24 \mathrm{~h}$ of sustained hypoxia (Fig. 5). No significant alteration, however, was observed between episodic and short-term ( $4 \mathrm{~h})$ hypoxia. Similar results were obtained by detection of HIF target genes (Fig. 6). All tested HIF target genes were significantly different in episodic hypoxia as compared to sustained hypoxia. Thus, collectively, these data confirm a lack in transcriptional activity of HIF-1 despite increased accumulation of the HIF- $1 \alpha$ protein, supporting the view that episodic hypoxia causes the lack in HIF response observed in CsA treated mice (Fig. 3).

\section{Episodic hypoxia impairs nuclear localization of HIF-1 $\alpha$}

To address the question of how episodic hypoxia impairs HIF activity, we investigated the nuclear localization of HIF- $1 \alpha$ that is a prerequisite for its association with HIF- $1 \beta$ and downstream transcription factor function. We prepared nuclear and cytoplasmic extracts by differential centrifugation and analyzed for the presence of HIF- $1 \alpha$ in each fraction by Western blot analysis (Fig. 7A). Samples were processed in parallel for total extracts in order to visualize the net accumulation of HIF- $1 \alpha$ and show, as previously observed, a significant increase in HIF-1 $\alpha$ during episodic hypoxia compared to $24 \mathrm{~h}$ hypoxia (Fig. 7B). Interestingly, these cells accumulated the least amount of HIF- $1 \alpha$ in the nucleus, with a significantly decreased nuclear/cytoplasmic distribution when compared to both normoxia and to cells exposed to long-term hypoxia (Fig. 7C). This indicates an impaired localization of the newly stabilized HIF- $1 \alpha$ to the nucleus and demonstrates subcellular distribution of HIF- $1 \alpha$ to be a contributing factor in episodic hypoxia. 


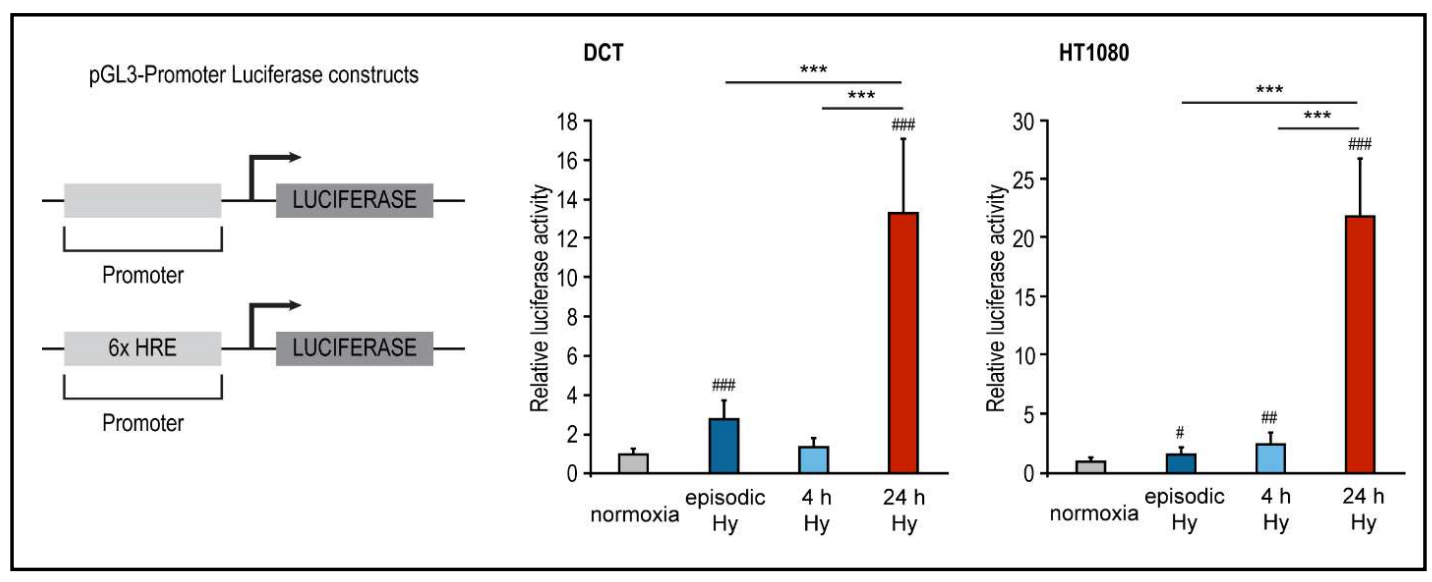

Fig. 5. Limited HIF-1 transcriptional activity in episodic hypoxia. Cells were transfected with a pGL3Promoter Luciferase construct and its modified variant containing six hypoxia-response elements (6x HRE). Schematic of the used promoter constructs is shown in the left panel. Hypoxia typically induces an increase in 6x HRE-dependent transcription via HIF-1 $\alpha$ stabilization and a subsequent increase in HIF-1 activity. Following exposure to the different types of hypoxia, HRE-dependent transcription of the luciferase gene was measured directly in cellular extracts from DCT (middle panel) and HT1080 (right panel) cells. Transfection efficiency was normalized to the co-transfected renilla luminescence values. Data are expressed relative to the reporter construct without the 6x HRE. Error bars indicate standard deviation $(n=8)$. Significance to normoxia: \#: $\mathrm{p}<0.05, \# \#$ : $\mathrm{p}<0.01$, \#\#\#: $\mathrm{p}<0.001$. Asterisks denote significance between hypoxic groups. ${ }^{* * *}$ : $\mathrm{p}<0.001$.

ROS produced by re-oxygenation following different forms of hypoxia

To find out whether CsA mediated episodic hypoxia causes specific adaptations despite of the lacking HIF response, we went back to our findings by microarray analysis in CsA treated mice (Table 1). Notably, Gene Ontology analysis indicated activation of the Glutathione system by CsA, which is crucial to prevent from ROS damage. Since, by definition, episodic hypoxia consists of hypoxia/re-oxygenation cycles, an acknowledged source of ROS. Thus, we next screened the transcriptome of CsA-induced episodic hypoxia for ROS scavengers. Indeed, we found nine different transcripts associated with the glutathione antioxidant system that were significantly up-regulated (Fig. 8A, upper panel) with respect to controls. This is in contrast to VHL-KO, the benchmark of HIF-activation, where the same nine candidates were either unchanged or significantly down-regulated (Fig. 8A, lower panel). Obviously, beside the HIF response, activation of ROS detoxification is a hallmark of episodic hypoxia. To verify these observations in vitro, we quantified ROS production in renal cells returning to normoxia for $1 \mathrm{~h}$ after either episodic, short-term, or sustained hypoxia (Fig. 8B). ROS levels after short-term hypoxia were similar to controls. Interestingly, ROS levels after episodic hypoxia, were modestly, but significantly increased albeit candidate genes of the glutathione system are supposed to be elevated. As expected, ROS levels after sustained hypoxia were markedly increased, and significantly with respect to episodic hypoxia (Fig. 8B).

Our data show that episodic hypoxia leads to a modest increase in ROS, as well as to increased defence against ROS, which most likely is triggered by HIF-independent mechanisms.

\section{Episodic hypoxia protects against apoptosis in vitro}

Since our in vivo and in vitro data indicate that episodic hypoxia is associated with a defence against ROS, we next tested if this translated into a better cell survival in a toxic environment. To this end, cells were pre-exposed to either episodic, short-term, or sustained hypoxia. Then, cells were challenged with staurosporine to induce apoptosis under conditions of re-oxygenation (Fig. 9). Active caspase-3 served as a quantitative marker of apoptosis (Fig. 


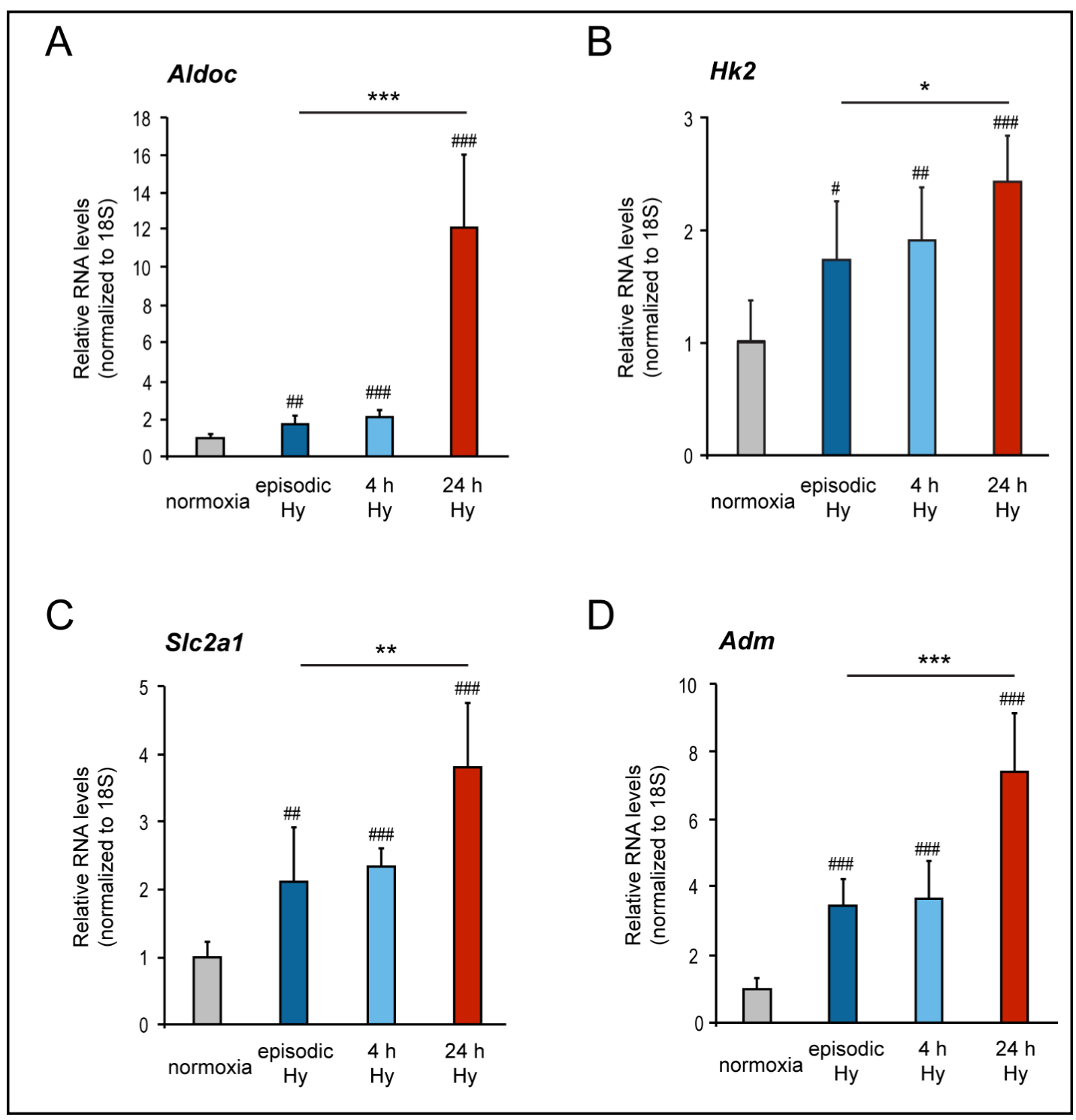

Fig. 6. Limited HIF-1 transcriptional response in episodic hypoxia. Real time PCR analysis of HIF-1 target genes (A) aldolase C (Aldoc), (B) hexokinase 2 (HK2), (C) solute carrier family 2 (Slc2a1, alias Glut1), and (D) adrenomedullin (Adm) in DCT cells. Values were normalized to 18S ribosomal RNA and significant differences to normoxia indicated with hash signs \#\#\#: $<<0.001$, \#\#: $\mathrm{p}<0.01$. Asterisks denote significance between hypoxic groups. ${ }^{* *}$ : $\mathrm{p}<0.01$, and ${ }^{* * *}$ : $\mathrm{p}<0.001$. Error bars indicate standard deviation $(\mathrm{n}=6)$.

9A, D). Pre-treatment with episodic hypoxia significantly reduced staurosporine-induced apoptosis, when compared with both short-term and sustained hypoxia. We further assessed HIF- $1 \alpha$ protein levels under staurosporine treatment. With respect to normoxic controls, all three hypoxic pre-treatment protocols led to a depression of HIF-1 $\alpha$ under staurosporine (Fig. 9A, B), and this effect was most pronounced after sustained hypoxia.

Remarkably, episodic hypoxia showed the least degree of apoptosis, even when compared to $4 \mathrm{~h}$ hypoxia, a finding that suggests that repetitive episodic hypoxia provides protection against apoptosis. As HIF- $1 \alpha$ levels and activity, as well as HIF target gene expression showed no differences between short term hypoxia and episodic hypoxia, we conclude that episodic hypoxia mainly mediates protection against re-oxygenation triggered ROS. 
Fig. 7. Reduced nuclear accumulation of HIF-1 $\alpha$ in episodic hypoxia. (A) Representative Western blot of HIF- $1 \alpha$ protein levels in total, nuclear and cytosolic fractions after exposure of DCT cells to different types of hypoxia. Tubulin was used as a cytosolic marker and acetyl histone H3 served as a nuclear marker. (B) Quantitation of HIF-1 $\alpha$ protein levels in total cell lysates. Note the stronger increase in HIF1 $\alpha$ level in episodic hypoxia relative to $24 \mathrm{~h}$ of hypoxia. (C) Nuclear/ cytoplasmic ratio of HIF$1 \alpha$ protein levels with normoxia set at 1 . While following $24 \mathrm{~h}$ of hypoxia HIF-1 $\alpha$ predominantly accumulates in the nucleus, episodic hypoxia causes a low nuclear/cytoplasmic ratio. Significance to normoxia \#: $\mathrm{p}<0.05$, \#\#: $\mathrm{p}<0.01$, \#\#\#: $\mathrm{p}<0.001$. Asterisks denote significance between hypoxic groups. ***: $\mathrm{p}<0.001$. Error bars indicate standard deviation $(n=3)$.
A
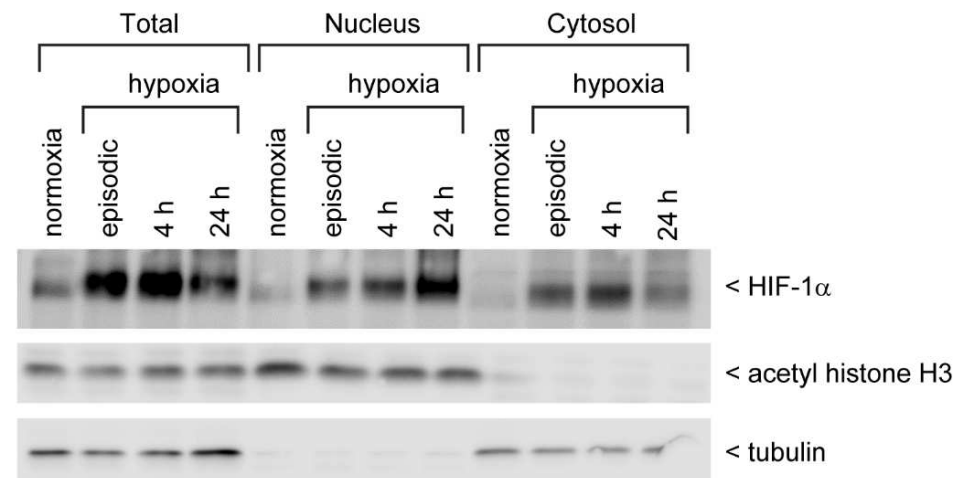

B

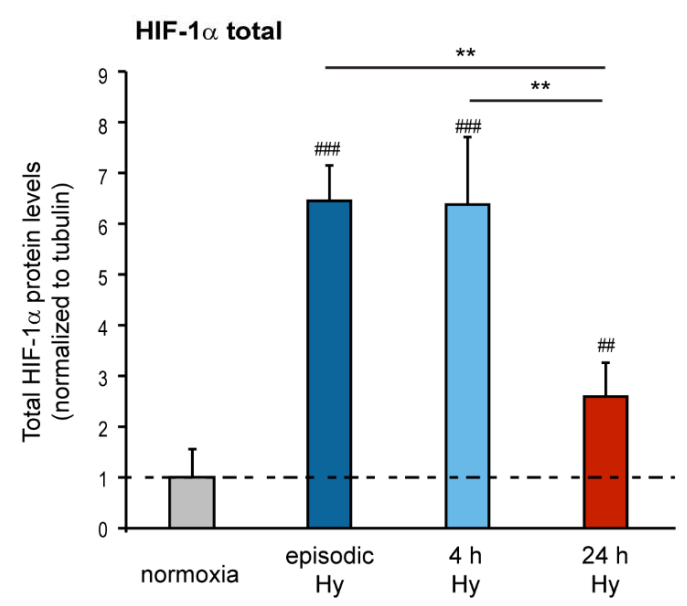

C

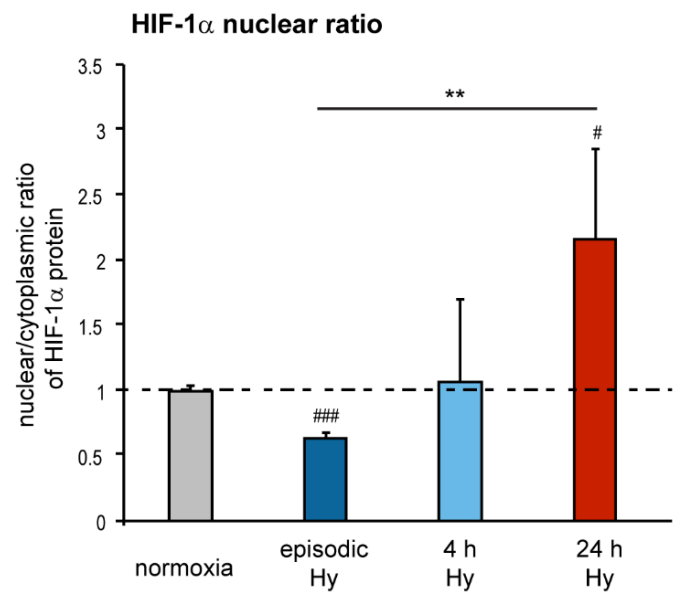




\section{Discussion}

Although hypoxia was generally regarded as detrimental [2527], preconditioning to hypoxia and intermittent hypoxia may have a beneficial impact on cell differentiation and survival [28-31]. Obviously, hypoxia is of double nature, depending on its extent, length, and timing. Here we systematically studied episodic hypoxia, as a distinct type occurring in both health and disease. Our key findings are that 1) Episodic hypoxia induces a specific transcriptome, which is distinct from that observed after sustained hypoxia; 2) In episodic hypoxia a disparity occurs between marked HIF$1 \alpha$ accumulation, and low HIF target gene expression; 3) Episodic hypoxia mounts defence against cellular stress; 4) Pre-treatment with episodic hypoxia protects against apoptosis.

This study

represents continuation a our previous work demonstrating that in vivo daily CsA treatment provokes episodic hypoxia to the kidney [11]. By global gene expression analysis we confirmed that CsA mediated episodic hypoxia in vivo is virtually unable to up-

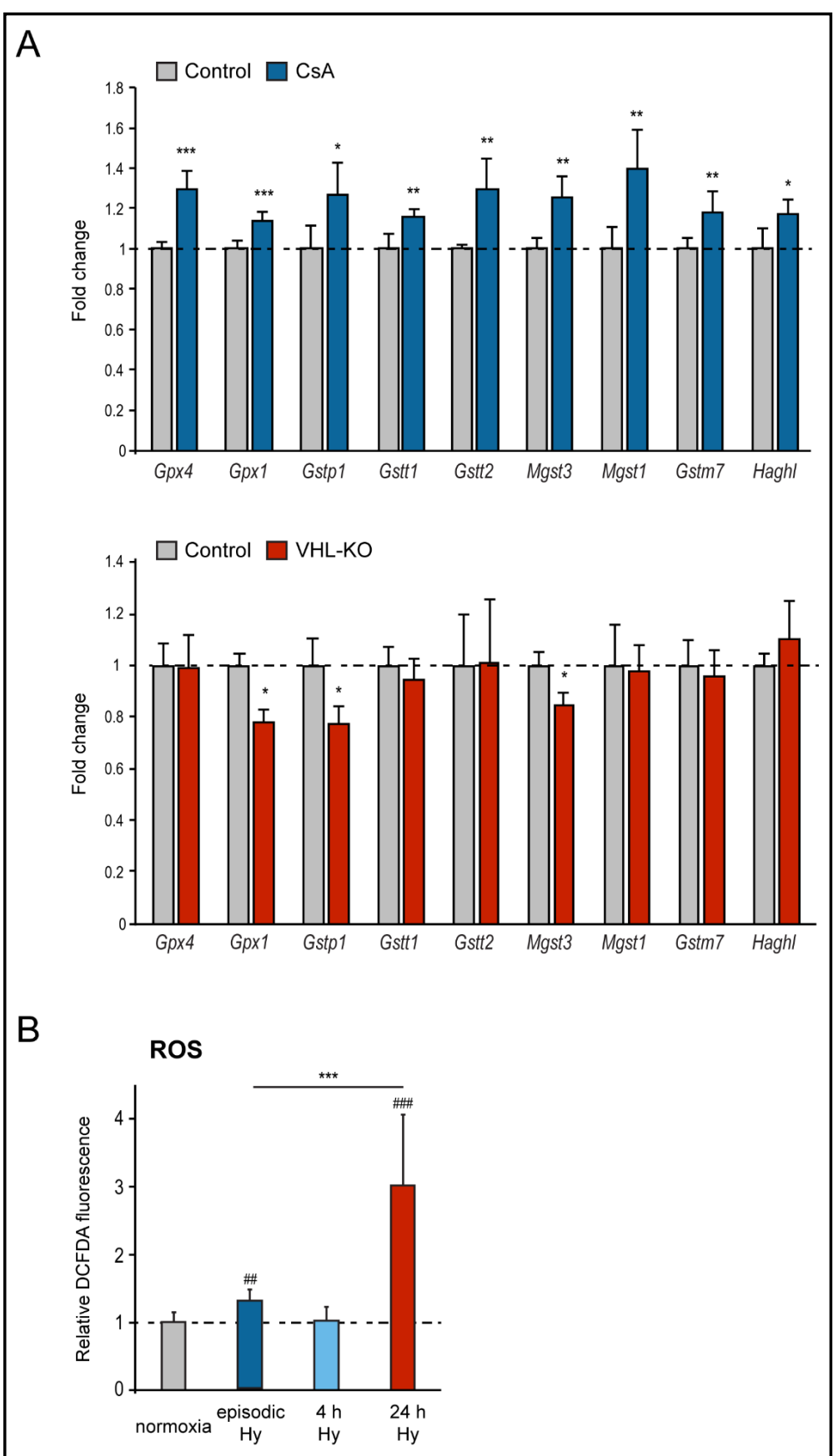

Fig. 8. Episodic hypoxia induces antioxidant mechanisms and attenuates ROS production. (A) Microarray analysis of expression level changes of genes associated with antioxidant defense in CsA treated mice (upper panel, $n=5$ each) and in mice with induced tubular-specific VHL-KO (lower panel; data taken from GSE44925) [21]. *: $\mathrm{p}<0.05,{ }^{* *}: \mathrm{p}<0.01,{ }^{* * *}: \mathrm{p}<0.001$. Error bars indicate standard deviation. (B) Cellular ROS production in DCT cells after exposure to different types of hypoxia followed by $1 \mathrm{~h}$ re-oxygenation was monitored by 2', 7'-dichlorofluorescein diacetate (DCFDA) assay. Significance to normoxia \#\#: $p<0.01$, \#\#: $p<0.001$. Asterisks denote significance between hypoxic groups. ${ }^{* * *}$ : $\mathrm{p}<0.001$. Error bars indicate standard deviation of three independent biological experiments, each with 10 replicates. 


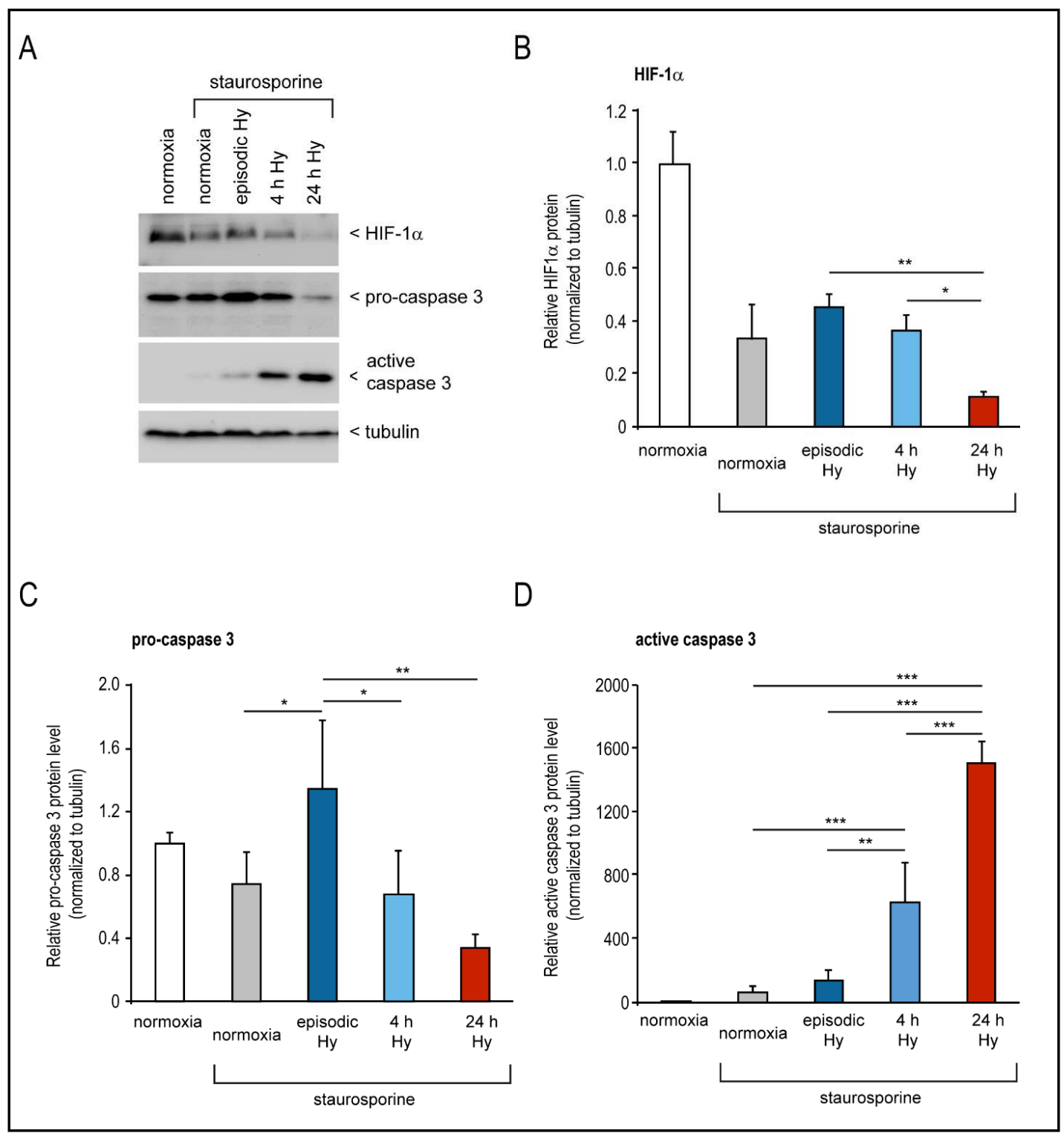

Fig. 9. Episodic hypoxia provides resistance to apoptosis. (A) Representative Western blot of HIF-1 $\alpha$, Procaspase- 3 and active Caspase- 3 after apoptosis induction with $1 \mu \mathrm{M}$ staurosporine during $3 \mathrm{~h}$ reoxygenation. DCT cells were prior exposed to the different types of hypoxia. Tubulin served as a loading control. (B) Quantitation of HIF-1 $\alpha$ protein levels. Asterisks denote significance between staurosporine treated groups $*$ : $\mathrm{p}<0.05,{ }^{* *}: \mathrm{p}<0.01,{ }^{* * *}: \mathrm{p}<0.001$. Error bars indicate standard deviation $(\mathrm{n}=3)$. (C) Quantitation of Procaspase-3 protein levels as in (B). (D) Quantitation of active Caspase-3 protein levels as in (B). Shown in white bars in each graph are the protein levels in untreated cells in normoxia. This can be used as a comparison for the effect of staurosporine on apoptosis in the absence of hypoxia in these cells.

regulate HIF target genes although HIF- $1 \alpha$ strongly accumulates.

To expand our in vivo work, we have created an in vitro protocol of episodic hypoxia, which, by its design, can easily be compared with either short-term, or sustained hypoxia. The latter is the benchmark protocol for HIF target gene up-regulation in vitro.

Our experiments conducted with two different cell lines (renal mouse and human fibrosarcoma cells) confirm the lack of HIF target gene up-regulation by episodic hypoxia as observed following daily CsA treatment for one week. We observed that, in contrast to sustained hypoxia, in episodic hypoxia the nuclear to cytoplasm ratio for HIF-1 $\alpha$ is shifted 
in favor of the cytoplasm, thus precluding HIF's binding to DNA and explaining, at least in part, the unexpected low HIF response. Such mis-location of HIF-1 $\alpha$ is remarkable, and in contradiction with the current view of a rapid and unrestricted nuclear translocation, combined with a rapid cytoplasmic degradation of HIF-1 $\alpha$ [32-35]. The mechanisms behind cytoplasmic accumulation of HIF- $1 \alpha$, as well as its potential role in cellular adaptation need further investigation. However, our data show that 4 hours of hypoxia are insufficient to activate a proper HIF response and HIF- $1 \alpha$ rapidly declines following re-oxygenation. The latter effect is attributed to hypoxic up-regulation of PHDs that elevate activity during reoxygenation [36]. Thus, a cellular memory effect may exist that prevents a potentially maladaptive elevation of transcriptional HIF activity under conditions of repetitive short-term hypoxia cycles.

Although we were able to reproduce in vivo findings of repetitive CsA treatment by episodic hypoxia in vitro, it is suggested that CsA affects further mechanisms. Previously, it has been shown that, in vitro, CsA prevented most of the hypoxia-induced HIF-1 $\alpha$ stabilization by a single CsA dose and this inhibitory action of CsA requires a functional proteasomal machinery [19]. In contrast, we found marked accumulation of HIF-1 $\alpha$ in kidneys of mice following daily cycles of CsA and in renal cells exposed to repetitive short-term (episodic) hypoxia. Thus, our findings indicate a mechanism different from HIF- $1 \alpha$ hydroxylation and proteasomal degradation. As we observed inhibited HIF- $1 \alpha$ nuclear localization, we assume that depending on timing, application as well as cell type, different mechanisms exist to prevent HIF activity following CsA and/ or episodic hypoxia.

Pathway enrichment analysis predicts that CsA mediated episodic hypoxia mounts a specific defence against cellular stress. Assuming that repetitive hypoxia/re-oxygenation episodes would boost cellular defence against ROS led us to test for transcripts involved in protection against ROS. Indeed, nine such candidates associated with the glutathione antioxidant system were significantly up-regulated in CsA induced episodic hypoxia. In line with the limited HIF response, these data confirm that episodic hypoxia shapes a specific cell protective transcriptome, different from sustained hypoxia. Quantification of ROS generation upon re-oxygenation in vitro revealed that short-term hypoxia was comparable to controls and, as expected, sustained hypoxia/ re-oxygenation caused marked elevation in ROS. Episodic hypoxia, namely the daily repetition of short-term hypoxia, produced a modest, but significant increase. ROS have been implicated in a series of physiological and pathophysiological pathways [37]. While severe increases of ROS, as detected after sustained hypoxia, may be detrimental [38], modest increases of ROS may confer protection against cellular stress [39-43]. Supporting, mild elevations of ROS, as observed in our study following episodic hypoxia, has been also reported under CsA treatment in vivo [13]. Conceivably, moderate elevated ROS levels may trigger cellular defence mechanisms.

The striking and most specific effect of episodic hypoxia was observed by induction of apoptosis during re-oxygenation. Apoptosis was most pronounced when cells were subjected to sustained hypoxia/re-oxygenation and challenged with staurosporine, a competitive inhibitor of ATP binding to a series of kinases [44, 45]. Marked elevation of the apoptosis marker active caspase- 3 was also found by pre-treatment with short-term hypoxia. By contrast, pre-treatment with episodic hypoxia conferred marked protection from staurosporine-induced apoptosis. Thus, the unique character of episodic hypoxia seems to be resistance to ROS mediated cell stress following re-oxygenation. Interestingly, in this setting HIF-1 $\alpha$ protein, though depressed with respect to untreated controls, was highest after episodic hypoxia, and lowest after sustained hypoxia. Obviously, strong HIF$1 \alpha$ accumulation during episodic hypoxia persists following re-oxygenation. We can only speculate if this difference in HIF-1 $\alpha$ protein may translate into a survival benefit. At least within three hours of staurosporine toxicity, pre-existing HIF target genes, as built up by sustained hypoxia, could not prevent cell death.

Moving back to our initial in vivo experiment [11], and in light of our in vitro data, CsAinduced episodic hypoxia may elicit some cell protective mechanisms, at least in the shortterm, despite of its acknowledged renal toxicity in the long-term. While in sustained hypoxia 


\section{\begin{tabular}{ll} 
Cellular Physiology & Cell Physiol Biochem 2019;52:1075-1091 \\
\hline DOl: 10.33594/000000073 & 2019 The Author(s). Published by
\end{tabular}

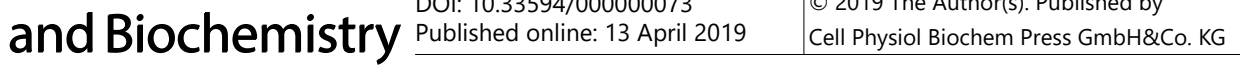 \\ Heß et al.: Episodic Hypoxia Protects from Cell Stress}

the protective cellular response is mainly attributed to HIF, during episodic hypoxia, the rescue program involves ROS detoxification by the glutathione system. Moderate elevated ROS levels, persistent HIF-1 $\alpha$ accumulation and resistance to apoptosis represent key features of our episodic hypoxia setting. Expanding this concept may lead to new perspectives on other physiological and patho-physiological conditions of episodic hypoxia/re-oxygenation, like e.g. endurance training, intermittent claudicatio, sleep apnea etc.. Whether the modest increase in ROS or the lack of a HIF response determines CsA mediated nephrotoxicity in the long term, needs to be addressed in future studies.

\section{Conclusion}

We provide evidence for a specific cell protective re-programming induced by episodic hypoxia. Pre-conditioning with episodic hypoxia may become a tool to ameliorate organ damage under stress.

\section{Acknowledgements}

This study was supported by the German Research Foundation (Deutsche Forschungsgemeinschaft, DFG) FOR-1368 (FA 845/4-2; RO 2449/2-2) and Else KrönerFresenius-Stiftung (2016_A207). We would like to thank Jeannette Schmidt for excellent technical assistance.

\section{Disclosure Statement}

All authors declare no conflicts of interest.

\section{References}

1 Almendros I, Farre N: Obstructive Sleep Apnea and Atherosclerosis: Both the Gut Microbiome and Hypercapnia Matter. Am J Respir Cell Mol Biol 2017;57:501-503.

2 Fletcher EC: Cardiovascular consequences of obstructive sleep apnea: experimental hypoxia and sympathetic activity. Sleep 2000;23 Suppl 4:S127-131.

3 Martin RJ, Wang K, Koroglu O, Di Fiore J, Kc P: Intermittent hypoxic episodes in preterm infants: do they matter? Neonatology 2011;100:303-310.

Grace PA: Ischaemia-reperfusion injury. Br J Surg 1994;81:637-647.

- 5 Hellwig-Burgel T, Stiehl DP, Wagner AE, Metzen E, Jelkmann W: Review: hypoxia-inducible factor-1 (HIF-1): a novel transcription factor in immune reactions. J Interferon Cytokine Res 2005;25:297-310.

6 Loboda A, Jozkowicz A, Dulak J: HIF-1 and HIF-2 transcription factors--similar but not identical. Mol Cells 2010;29:435-442.

7 Ravenna L, Salvatori L, Russo MA: HIF3 $\alpha$ : the little we know. FEBS J 2016;283:993-1003.

- 8 Koh MY, Powis G: Passing the baton: the HIF switch. Trends Biochem Sci 2012;37:364-372.

- 9 Kong X, Alvarez-Castelao B, Lin Z, Castano JG, Caro J: Constitutive/hypoxic degradation of HIF-alpha proteins by the proteasome is independent of von Hippel Lindau protein ubiquitylation and the transactivation activity of the protein. J Biol Chem 2007;282:15498-15505.

10 Azzi JR, Sayegh MH, Mallat SG: Calcineurin inhibitors: 40 years later, can't live without. J Immunol 2013;191:5785-5791.

11 Fähling M, Mathia S, Scheidl J, Abramovitch R, Milman Z, Paliege A, Peters H, Persson PB, Heyman SN, Rosenberger C: Cyclosporin a induces renal episodic hypoxia. Acta Physiol (Oxf) 2017;219:625-639.

- 12 Baxter CR, Duggin GG, Willis NS, Hall BM, Horvath JS, Tiller DJ: Cyclosporin A-induced increases in renin storage and release. Res Commun Chem Pathol Pharmacol 1982;37:305-312. 


\section{Cellular Physiology and Biochemistry}

Cell Physiol Biochem 2019;52:1075-1091

\begin{tabular}{l|l}
\hline DOI: 10.33594/000000073 & ( 2019 The Author(s). Published by
\end{tabular}

Published online: 13 April $2019 \quad$ Cell Physiol Biochem Press GmbH\&Co. KG

Heß et al.: Episodic Hypoxia Protects from Cell Stress

13 Damiano S, Trepiccione F, Ciarcia R, Scanni R, Spagnuolo M, Manco L, Borrelli A, Capasso C, Mancini R, Schiattarella A, Iervolino A, Zacchia E, Bata-Csere A, Florio S, Anastasio P, Pollastro R, Mancini A, Capasso G: A new recombinant MnSOD prevents the cyclosporine A-induced renal impairment. Nephrol Dial Transplant 2013;28:2066-2072.

- 14 Kriz W: Structural organization of the renal medulla: comparative and functional aspects. Am J Physiol 1981;241:R3-16.

- 15 Brezis M, Rosen S: Hypoxia of the renal medulla--its implications for disease. N Engl J Med 1995;332:647655.

- 16 Haase VH: Hypoxia-inducible factor signaling in the development of kidney fibrosis. Fibrogenesis Tissue Repair 2012;5:S16.

- 17 Higgins DF, Kimura K, Bernhardt WM, Shrimanker N, Akai Y, Hohenstein B, Saito Y, Johnson RS, Kretzler M, Cohen CD, Eckardt KU, Iwano M, Haase VH: Hypoxia promotes fibrogenesis in vivo via HIF-1 stimulation of epithelial-to-mesenchymal transition. J Clin Invest 2007;117:3810-3820.

18 Kong X, Lin Z, Caro J: Immunophilin-ligands FK506 and CsA inhibit HIF1alpha expression by a VHL- and ubiquitin-independent mechanism. FEBS Lett 2006;580:6182-6186.

19 D’Angelo G, Duplan E, Vigne P, Frelin C: Cyclosporin A prevents the hypoxic adaptation by activating hypoxia-inducible factor-1alpha Pro-564 hydroxylation. J Biol Chem 2003;278:15406-15411.

- 20 Mathia S, Paliege A, Koesters R, Peters H, Neumayer HH, Bachmann S, Rosenberger C: Action of hypoxiainducible factor in liver and kidney from mice with Pax8-rtTA-based deletion of von Hippel-Lindau protein. Acta Physiol (Oxf) 2013;207:565-576.

- 21 Fähling M, Mathia S, Paliege A, Koesters R, Mrowka R, Peters H, Persson PB, Neumayer HH, Bachmann S, Rosenberger C: Tubular von Hippel-Lindau knockout protects against rhabdomyolysis-induced AKI. J Am Soc Nephrol 2013;24:1806-1819.

- 22 Wang J, Vasaikar S, Shi Z, Greer M, Zhang B: WebGestalt 2017: a more comprehensive, powerful, flexible and interactive gene set enrichment analysis toolkit. Nucleic Acids Res 2017;45:W130-W137.

23 Fähling M, Mrowka R, Steege A, Martinka P, Persson PB, Thiele BJ: Heterogeneous nuclear ribonucleoprotein-A2/B1 modulate collagen prolyl 4-hydroxylase, alpha (I) mRNA stability. J Biol Chem 2006;281:9279-9286.

24 Fahling M: Cellular oxygen sensing, signalling and how to survive translational arrest in hypoxia. Acta Physiol (Oxf) 2009;195:205-230.

25 Filippi I, Saltarella I, Aldinucci C, Carraro F, Ria R, Vacca A, Naldini A: Different Adaptive Responses to Hypoxia in Normal and Multiple Myeloma Endothelial Cells. Cell Physiol Biochem 2018;46:203-212.

26 Liu ZZ, Bullen A, Li Y, Singh P: Renal Oxygenation in the Pathophysiology of Chronic Kidney Disease. Front Physiol 2017;8:385.

- 27 West JB: Physiological Effects of Chronic Hypoxia. N Engl J Med 2017;376:1965-1971.

- 28 Heyman SN, Leibowitz D, Mor-Yosef Levi I, Liberman A, Eisenkraft A, Alcalai R, Khamaisi M, Rosenberger C: Adaptive response to hypoxia and remote ischaemia pre-conditioning: a new hypoxia-inducible factors era in clinical medicine. Acta Physiol (Oxf) 2016;216:395-406.

29 Kapitsinou PP, Haase VH: Molecular mechanisms of ischemic preconditioning in the kidney. Am J Physiol Renal Physiol 2015;309:F821-834.

30 Li S, Hafeez A, Noorulla F, Geng X, Shao G, Ren C, Lu G, Zhao H, Ding Y, Ji X: Preconditioning in neuroprotection: From hypoxia to ischemia. Prog Neurobiol 2017;157:79-91.

31 Wang C, Li H, Wang S, Mao X, Yan D, Wong SS, Xia Z, Irwin MG: Repeated Non-Invasive Limb Ischemic Preconditioning Confers Cardioprotection Through PKC-/STAT3 Signaling in Diabetic Rats. Cell Physiol Biochem 2018;45:2107-2121.

32 Depping R, Jelkmann W, Kosyna FK: Nuclear-cytoplasmatic shuttling of proteins in control of cellular oxygen sensing. J Mol Med (Berl) 2015;93:599-608.

33 Kallio PJ, Okamoto K, O’Brien S, Carrero P, Makino Y, Tanaka H, Poellinger L: Signal transduction in hypoxic cells: inducible nuclear translocation and recruitment of the $\mathrm{CBP} / \mathrm{p} 300$ coactivator by the hypoxiainducible factor-1alpha. EMBO J 1998;17:6573-6586.

34 Huang LE, Arany Z, Livingston DM, Bunn HF: Activation of hypoxia-inducible transcription factor depends primarily upon redox-sensitive stabilization of its alpha subunit. J Biol Chem 1996;271:32253-32259. 


\section{Cellular Physiology Cell Physiol Biochem 2019;52:1075-1091

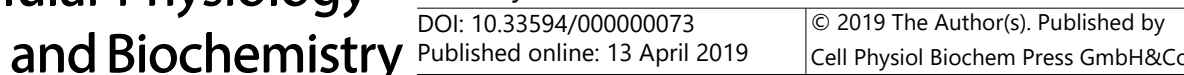 \\ Heß et al.: Episodic Hypoxia Protects from Cell Stress}

35 Salceda S, Caro J: Hypoxia-inducible factor 1alpha (HIF-1alpha) protein is rapidly degraded by the ubiquitin-proteasome system under normoxic conditions. Its stabilization by hypoxia depends on redoxinduced changes. J Biol Chem 1997;272:22642-22647.

- 36 D’Angelo G, Duplan E, Boyer N, Vigne P, Frelin C: Hypoxia up-regulates prolyl hydroxylase activity: a feedback mechanism that limits HIF-1 responses during reoxygenation. J Biol Chem 2003;278:3818338187.

- 37 Zuo L, Zhou T, Pannell BK, Ziegler AC, Best TM: Biological and physiological role of reactive oxygen species-the good, the bad and the ugly. Acta Physiol (Oxf) 2015;214:329-348.

- 38 Cannito S, Novo E, Compagnone A, Valfre di Bonzo L, Busletta C, Zamara E, Paternostro C, Povero D, Bandino A, Bozzo F, Cravanzola C, Bravoco V, Colombatto S, Parola M: Redox mechanisms switch on hypoxia-dependent epithelial-mesenchymal transition in cancer cells. Carcinogenesis 2008;29:2267-2278.

39 Haendeler J, Tischler V, Hoffmann J, Zeiher AM, Dimmeler S: Low doses of reactive oxygen species protect endothelial cells from apoptosis by increasing thioredoxin-1 expression. FEBS Lett 2004;577:427-433.

40 Chen TI, Hsu YC, Lien CF, Lin JH, Chiu HW, Yang KT: Non-lethal levels of oxidative stress in response to short-term intermittent hypoxia enhance $\mathrm{ca}(2)(+)$ handling in neonatal rat cardiomyocytes. Cell Physiol Biochem 2014;33:513-527.

41 Prabhakar NR, Kumar GK: Oxidative stress in the systemic and cellular responses to intermittent hypoxia. Biol Chem 2004;385:217-221.

- 42 Yuan G, Adhikary G, McCormick AA, Holcroft JJ, Kumar GK, Prabhakar NR: Role of oxidative stress in intermittent hypoxia-induced immediate early gene activation in rat PC12 cells. J Physiol 2004;557:773783.

- 43 Lien CF, Lee WS, Wang IC, Chen TI, Chen TL, Yang KT: Intermittent hypoxia-generated ROS contributes to intracellular zinc regulation that limits ischemia/reperfusion injury in adult rat cardiomyocyte. J Mol Cell Cardiol 2018;118:122-132.

44 Falcieri E, Martelli AM, Bareggi R, Cataldi A, Cocco L: The protein kinase inhibitor staurosporine induces morphological changes typical of apoptosis in MOLT-4 cells without concomitant DNA fragmentation. Biochem Biophys Res Commun 1993;193:19-25.

45 Tamaoki T, Nomoto H, Takahashi I, Kato Y, Morimoto M, Tomita F: Staurosporine, a potent inhibitor of phospholipid/Ca++dependent protein kinase. Biochem Biophys Res Commun 1986;135:397-402. 